\title{
Desain Ilustrasi Foto Pada Baju Kaos Dengan Media Fotografi Digital Pendukung Pariwisata Budaya Di Pura Tanah Lot Dan Taman Ayun
}

\author{
I MADE SARYANA ${ }^{1}$, ANIS RAHARJO ${ }^{2}$, AMOGA LELO OCTAVIANO ${ }^{3}$ \\ Program Studi Fotografi,Fakultas Seni Rupa \& Desain,Institut Seni Indonesia Denpasar \\ E-mail: made.saryana@ymail.com
}

\begin{abstract}
Penelitian ini bertujuan untuk mengembangkan industri kreatif dengan menerapkan fotografi digital melalui pengembangan produk instan dengan desain ilustrasi foto pada baju kaos. Pemilihan Obyek wisata Pura Tanah Lot Tabanan dan Pura Taman Ayun Badung Bali, dijadikan obyek penelitian karena obyek wisata tersebut selalu ramai dikunjungi wisatawan. Pengumpulan data dilakukan dengan observasi, wawancara dan studi pustaka. Data yang diperoleh dari hasil observasi dan wawancara dianalisis dengan menggunakan metode penciptaan seni, sehingga hasil análisis dapat dijadikan pedoman atau konsep dasar dalam pengembangan produk sovenir baju kaos. Penelitian ini dilakukan dengan (1) Mengidentifikasi berbagai jenis sovenir baju kaos yang dijual pada kawasan obyek wisata Tanah Lot Tabanan dan Pura Taman Ayun Badung Bali, baik dari bahan, desain ilustrasinya serta teknik pembuatannya. (2) Menganalisis harga, tingkat penjualan, serta bahan, desain ilustrasinya dan teknik pembuatannya. (3). Melakukan eksperimen desain ilustrasi foto dengan fotografi digital dan pengolahan melalui komputer. (4) Pembuatan ilustrasi foto dan menerapkannya dengan fotografi dan sablon digital pada baju kaos.
\end{abstract}

Kata kunci: Inovasi desain ilustrasi foto, Baju kaos, Obyek wisata Pura Tanah Lot dan Pura Taman Ayun

\section{Photo Illustration On T-Shirt With Digital Pohotograhy Media To Support Tourism And Culture At Tanah Lot Temple And Taman Ayun}

This research started with observation of several tourism destinations in Bali such as Tanah Lot in Tabanan and Taman Ayun Badung. The observation is that by taking pictures of tourists and then selling it on photo printed paper, profit margins are minimized. Furthermore, selling t-shirts as souvenirs on which the design is lacking in representation of the location show restricted and minimized monetization capabilities. Based on these observations, the researcher intends to conduct research while creating an innovative product which is capable of representing the aforementioned locations. Through implementation of digital photography and patternization modalities, designed photos can instantaneously be printed on the t-shirt, and automatically it may be worn by tourists. This technique can prove to have drastic impact upon the profit margins of vendors in comparison to conventional modalities. The aim of the research is to develop creative industry by applying digital photography through the development of instant product through creative design on t-shirts. The option to choose Tanah Lot and Taman Ayun temples because these toruism objects are of the most favorite tourism destinations steadily receive visitation from many tourists from all around the world. This research focuses on (1) The identification of T-shirts as souvenirs sold in Tanah Lot temple in Tabanan and Taman Ayun temple in Badung, based on fabric, lllustration design and the production techniques. (2) Price analysis, seeling rank, fabric, illustration design and production techniques; (3) To conduct experimental photography llustration design through digital photography and computer-driven image processing; (4) The production of photo llustration and digital patterns on t-shirts. Data collection is taken based on observation, interviews and library research. The data is analyzed using art creation method therefore it can be used as guidance or a basic concept in developing t-shirts as souvenirs.

Keywords: Innovation on photo design illustration, T-shirts, Tourism Desatination of Tanah Lot and Taman Ayun temples. 


\section{PENDAHULUAN}

Penelitian ini diawali dengan pengamatan penulis terhadap beberapa obyek wisata yang ada di Bali, utamanya adalah Pura Tanah Lot Tabanan dan Pura Taman Ayun Badung Bali, di mana para fotografer memotret wisatawan dilokasi tersebut dan hasilnya dijual dengan cetakan foto di kertas. Keuntungan dari menjual foto yang dicetak di kertas tentu sangatlah kecil. Demikian juga souvenir berupa baju kaos yang dijual pada obyek wisata tersebut hampir sama terutama dari desain dan ilustrasinya, sehingga kurang memiliki identitas yang dapat mewakili masing-masing obyek wisata tersebut. Berdasarkan permasalahan tadi penulis mengadakan penelitian dan membuat produk inovatif yang mencerminkan identitas masing-masing obyek wisata tersebut. Dengan memanfaatkan fotografi digital dan sablon digital, foto yang dihasilkan, kemudian didesain sedemikian rupa di komputer dan langsung ditransper ke baju kaos. Dengan kecanggihan teknologi digital hanya dalam hitungan menit baju sudah bisa langsung dipakai wisatawan. Tentunya produk ini memberikan keuntungan yang berlipat dibandingkan kalau foto hanya dicetak dengan cara yang konvensional. Dengan menjual produk sedikit untungnya lebih maksimal.

Pada saat ini hampir setiap sektor kehidupan memanfaatkan jasa fotografi, dari dokumentasi, promosi sampai pada usaha-usaha yang kreatif. Fotografi telah diidentifikasi sebagai industri kreatif oleh Pemerintah, di mana lingkup industri kreatif mencakup 14 subsektor, antara lain: arsitektur, periklanan, barang seni (lukisan, patung), kerajinan, disain, mode/fesyen, musik, permainan interaktif, seni pertunjukan, penerbitan-percetakan, layanan komputer dan piranti lunak (software), radio dan televisi, riset dan pengembangan, film-video serta fotografi. Tiga subsektor yang memberikan kontribusi paling besar nasional adalah fashion (30\%), kerajinan (23\%) dan periklanan $(18 \%)$, sedangkan bidang yang lainnya perlu dikembangkan terus agar dapat memberikan kontribusi yang lebih banyak untuk kesejahteraan masyarakat. (Sudayat: 2015,14).

Berkembangnya teknologi di bidang fotografi, belum banyak dimanfaatkan oleh masyarakat Bali secara umum, khususnya masyarakat yang memiliki usaha di sekitar obyek wisata Pura Tanah Lot, Tabanan dan Pura Taman Ayun, Badung, Bali. Pengamatan penulis secara umum belum ada produk sovenir yang dihasilkan dengan memanfaatkan fotografi digital untuk dapat memberikan nilai tambah pada produk sovenir/kerajinan yang dihasilkan, padahal teknologi digital ini memberikan solusi untuk dapat menghasilkan produk yang instan. Kecanggihan teknologi digital dan teknologi pendukungnya, memungkinkan fotografi digital dapat diterapkan pada berbagai benda yang dapat dijadikan sovenir termasuk baju kaos (t-shirt) yang selalu menjadi sovenir favorit bagi wisatawan. Kemajuan teknologi digital serta pendukungnya, menjadikan fotografi tidak hanya dapat dicetak secara konvensional yaitu di kertas, akan tetapi dapat dicetak di berbagai permukaan benda yang datar. Sebelum ditemukan teknologi digital ini, untuk memindahkan foto berwarna ke baju kaos membutuhkan waktu relatif lebih lama dan rumit, di mana proses tersebut hanya bisa dilakukan dengan proses sablon, melalui pembuatan film separasi terlebih dulu. Selain proses yang lebih lama dan rumit juga harus dipesan dalam jumlah yang banyak, karena ongkos produksi relatif tinggi. Namun di era digital ini semua serba memungkinkan dan memberikan peluang untuk dapat mengembangkannya lebih bervariatif, cepat dan dapat dipesan dalam jumlah terbatas/minimal dengan biaya yang relatif terjangkau, sehingga para pengusaha atau pencari nafkah di setiap obyek wisata dapat menerapkannya menjadi peluang usaha yang kreatif dan menguntungkan.

Pembuatan desain ilustrasi foto yang inovatif pada baju kaos yaitu dengan menampilkan obyek wisata atau bagian-bagian tertentu yang terdapat pada obyek tersebut dan wisatawan yang berkunjung dalam satu foto, kemudian foto tersebut ditransper ke baju kaos dan dalam hitungan menit baju tersebut sudah dapat dipakai. Dengan inovasi tersebut diharapkan dapat memberikan varian alternatif dalam usaha pengembangan produk souvenir bagi masyarakat pelaku usaha kecil menengah, sehingga dapat memberi nilai jual pada produk tersebut.

Dari paparan latar belakang di atas ada beberapa permasalahan dalam penelitian ini adalah:

Bagaimana jenis-jenis sovenir baju kaos dari bahan, desain ilustrasi pada baju kaos yang dijual di kawasan obyek wisata Tanah Lot dan Taman Ayun.

Bagaimana harga, tingkat penjualan, serta kualitas bahan, desain ilustrasinya dan teknik pembuatannya.

Bagaimana hasil eksperimen desain ilustrasi foto melalui pengolahan fotografi digital dan sablon digital.

Apakah desain ilustrasi foto yang diterapkan dengan fotografi dan sablon digital pada baju kaos diminati wisatawan. 
Penelitian ini menggunakan pendekatan kualitatif dan sumber data dikumpulkan dengan metode observasi, dokumentasi, wawancara dimana peneliti berperan sebagai instrumen penelitian. Teknik sampling dilakukan secara purposive sampling dan accidental sampling. Purposive sampling yaitu penentuan sampel dengan mempertimbangkan hal-hal tertentu yang dipandang dapat memberikan data secara maksimal. Penggunaan teknik sampling ini untuk mengambil sampel sovenir baju kaos yang berlokasi di tempat penjualan oleh-oleh pada obyek wisata di Pura Tanah Lot Tabanan dan di Pura Taman Ayun Badung. Sedangkan accidental sampling yaitu pengambilan sampel yang tidak dirancang pertemuannya terlebih dahulu, untuk mendapatkan data dari responden mengenai sovenir baju kaos. Sumber data dari responden dikumpulkan menggunakan metode wawancara, kuisioner dan metode sarasehan (FGD). Data-data dikumpulkan bersifat deskriptif. Berwujud kata-kata, kalimat-kalimat, paragraf-paragraf yang berbentuk narasi dan bersifat deskriptif (Arikunto, 2002:14).

Analisis data kualitatif merupakan strategi untuk mengorganisasikan data-data yang diperoleh melalui metode pengumpulan data pada tahap awal penelitian, untuk kemudian dikelompokan, diidentifikasi, disintesiskan agar bisa dikomunikasikan kepada orang lain dalam bentuk laporan (Bogdan \& Biklen 1982, dalam Moleong, 2014:149). Data-data penelitian dikumpulkan melalui metode dokumentasi, wawancara, kuisioner dan FGD. Sedangkan dalam penciptaan desain ilustrasi foto pada baju kaos menggunakan metode penciptaan karya seni, yaitu: eksplorasi, perancangan, dan perwujudan. Tahap eksplorasi meliputi aktivitas penjelajahan menggali sumber ide dengan langkah identifikasi dan perumusan masalah; penelusuran, penggalian, pengumpulan data dan referensi. Tahap perancangan yang dibangun berdasarkan perolehan butir penting hasil analisis yang dirumuskan, diteruskan visualisasi gagasan dalam bentuk desain alternatif. Kemudian dipertimbangkan dari berbagai aspek seperti: ekonomi, material, teknik, ergonomis, keseimbangan, dan berbagai unsur estetika. Tahap perwujudan, diawali dengan seleksi desain alternatif kemudian dipilih menjadi desain ilustrasi foto yang dianggap sempurna dengan pertimbangan komposisi, angle, estetika dan penyelesaian akhir (Sp. Gustami, 2007: 329-332).

\section{PEMBAHASAN}

Teknik sablon digital dengan mesin Hot Press atau teknik transfer print, merupakan perkembangan proses sablon terbaru, meskipun bukan murni teknik sablon konvensional, tapi banyak yang menggolongkan teknik ini ke bidang sablon. Teknik ini, dengan menggunakan lembaran aluminum foil yang khusus dikembangkan untuk pencetakan. Teknik ini memanfaatkan panas mesin Heat / Hot Press untuk melakukan pemindahan gambar sesuai dengan bentuk yang diinginkan. Untuk kain / kaos, sistem pemindahannya hanya membutuhkan lem perekat khusus untuk dapat merekatkan lembaran foil tersebut ke kain. Untuk menghasilkan bentuk gambar yang lebih maksimal, maka dapat menyablonkan lem terlebih dulu untuk foil tersebut dengan cara sablon yang seperti biasa, lalu tinggal melakukan pengepressan lembaran foil di atas lem yang telah disablonkan tersebut. Dengan adanya perkembangan dalam teknologi printer dan khususnya teknologi tintanya, yaitu tinta sublimasi, maka kita dapat melakukan proses transfer hasil print ke media yang diinginkan. Pentransferannya membutuhkan mesin heat/hot press, karena proses ini membutuhkan panas agar tinta sublim tersebut dapat berpindah ke media yang kita inginkan. (http://infohargamesinterbaru. blogspot.com).

Proses pemindahan gambar ke baju kaos baik warna putih/muda maupun baju berwarna (gelap) dilakukan dengan cara dan media/bahan yang berbeda tetapi keduanya harus melalui mesin hot press. Untuk baju kaos (khusus katun) berwarna putih/muda dapat menggunakan tinta yang umumnya dipakai pada printer biasa dan kertasnya menggunakan kertas yang khusus untuk baju warna putih/muda. Posisi gambar pada saat mengeprin dalam posisi mirror/terbalik karena gambar tersebut akan ditempel kepermukaan baju. Sedangkan waktu yang dibutuhkan dalam proses pemindahan gambar ke baju kaos sangat tergantung dengan jenis/merek kertas yang digunakan. Kertas transfer paper dengan merek blue print hanya membutuhkan waktu 2 menit dan panasnya mesin 200 derajat celsius. Setelah itu baju didiamkan agar dingin kemudian baru kertas dibuka (kelupas) secara perlahan dan gambar akan menepel pada baju kaos. Sedangkan jika printer yang digunakan dengan tinta khusus yaitu tinta sublim dapat diterapkan untuk baju kaos yang berwana warna putih/muda maupum baju berwarna (gelap) baik jenis kain katun maupun TC. Baju kaos warna gelap menggunakan kertas tranper paper yang khusus untuk warna gelap di mana gambar yang diprint dalam posisi normal karena pada saat pemindahannya gambar dalam posisi menhadap ke atas karena gambar harus dilepas terlebih dahulu dari kertas pelindungnya, kemudian baru ditempel pada baju kaos, sehingga membuat pemindahan gambarnya lebih rumit dibandingkan dengan baju kaos yang berwarna putih/muda.

Kunjungan wisatawan mancanegara ke obyek wisata Pura Tanah Lot lebih banyak dibandingkan dengan kunjungan wisatawan domestik. Berdasarkan data yang ada, pada semester pertama bulan Januari sampai Juni tahun 2017 ini kunjungan wisman ke 
Tabel 1. Jenis-jenis desain/gambar ilustrasi di baju kaos yang dijual pada Obyek Wisata Pura Tanah Lot dan Taman Ayun

\begin{tabular}{|l|l|l|}
\hline \multicolumn{2}{|c|}{ Obyek Wisata Pura Tanah Lot } & Obyek Wisata Taman Ayun \\
\hline TANAHLOSINSET &
\end{tabular}

Tanah Lot tercatat 954.744 orang. Sedangkan jumlah kunjungan wisdom tercatat 820.459 orang. Jadi total kunjungan wisman dan wisdom per enam bulan sebesar 1.775.203. Kalau dirata-rata perbulan yang bekunjung 295.867 orang dan perharinya sekitar 9.544 orang. (www.kabarnusa.com/2017/07/ wisatawan-mancanegara-masih-dominasi.html). Obyek wisata ini dikelola oleh manajemen profesional yang dipimpin oleh bapak I Ketut Toya Adnyana SP., dengan mengutamakan pemberdayaan masyarakat setempat. Seluruh pegawai dan pedagang berasal dari Desa Beraban yang merupakan lokasi obyek wisata Pura Tanah Lot. Jumlah pedagang secara keseluruhan adalah 262 orang, di mana 215 orang berjualan baju dan sovenir dan 47 orang berjualan makanan dan minuman, many changer serta telekomunikasi. Selain sebagai pedagang ada masyarakat yang mencari nafkah dengan menjadi fotografer yang berjumlah 170 orang. (Wawancara dengan Adi Susila, 21 Agustus 2017).

Sedangkan Taman Ayun dikelola Puri Mengwi, yaitu bapak I Made Suandi sebagai kepala pengelola yang membawahi 15 orang karyawan. Para pedagang dikelola oleh Desa, yaitu 16 orang pedagang yang menjual baju kaos dan sovenir.

Sesuai dengan data yang diperoleh dalam penelitian ini dapat dijabarkan sebagai berikut: Jenis-jenis baju kaos yang dijual pada obyek wisata Pura Tanah Lot dan Taman Ayun secara umum sama dengan apa yang dijual pada obyek wisata umumnya yang ada di Bali, terutama dari gambar/ilustrasinya serta bahannya. Dari data yang diperoleh pada obyek wisata Pura Tanah Lot dan Taman Ayun bahwa bahan kaos yang digunakan adalah sebagian besar menggunakan katun $20 \mathrm{~s}$, katun lacos dan sebagian kecil mori. dengan varian harga Rp. 30.000; sampai Rp. 100.000;. dengan tingkat penjualan bagus. Sedangkan di Tanah Lot ada yang menjual baju kaos katun $32 \mathrm{~s}$, dengan harga Rp. 500.000-1.000.000;. dengan tingkat penjualan sedang. Jadi kalau dilihat dari kualitasnya, ada yang sedang, bagus dan sangat bagus.

Teknik pembuatannya dengan sablon konvensional.
Sedangkan desainnya sebagian besar bertemakan seni budaya Bali dan sedikit mengenai seni budaya nusantara dan sangat sedikit yang mencerminkan obyek wisata Pura Tanah Lot dan sama sekali tidak mencerminkan identitas obyek wisata Pura Taman Ayun.

Dari data-data yang diperoleh di atas menunjukan bahwa gambar/ilustrasi yang digunakan pada baju kaos yang dijual pada obyek wisata Pura Tanah Lot dan Taman Ayun belum mencerminkan identitas kedua obyek tersebut, maka penelitian tentang sablon digital dengan membuat desain pada baju kaos dalam penelitian ini sangat memungkinkan menjadi solusi agar sovenir atau oleh-oleh yang dijual pada obyek tersebut mencerminkan obyek wisata Pura Tanah Lot dan Taman Ayun.

\section{Wujud Desain Baju Kaos Obyek Wisata Tanah Lot dan Taman Ayun}

Pada proses perwujudan desain dilakukan melalui beberapa tahapan yaitu eksplorasi, perancangan, dan perwujudan. Tahap eksplorasi dilakukan survey ke lokasi dan mendokumentasikan ikon-ikon yang ada dengan kamera untuk mendapatkan ide yang dapat mewakili identitas dari obyek wisata baik Tanah Lot maupun Taman Ayun. Ikon-ikon yang dimaksud adalah obyek pura itu sendiri dengan ciri khas lingkungannya, motif hias berupa ukiran, patung, relief serta tumbuhan, bunga dan daun. Data tersebut dijadikan dasar dalam pembuatan desain di mana sebelumnya sudah dilakukan seleksi. Selanjutnya data dianalisis apakah hal tersebut sudah mewakili masing-masing obyek tersebut, dirumuskan, kemudian diteruskan dengan visualisasi gagasan dalam beberapa bentuk rancangan desain alternatif, di mana dalam perancangan ini dilakukan eksperimen melalui komputer dengan menggunakan program photoshop CC 2015. Untuk mendapatkan desain yang sempurna dan mewakili identitas, baik Tanah Lot maupun Taman Ayun, maka desain dibuat dengan mempertimbangkan berbagai aspek seperti: nilai ekonomi, ergonomis, material dan tekniknya serta memenuhi kaedah estetika. Dalam penelitian ini dibuat tigapuluh jenis 
Tabel 2. Materi Desain : Obyek Wisata Tanah Lot

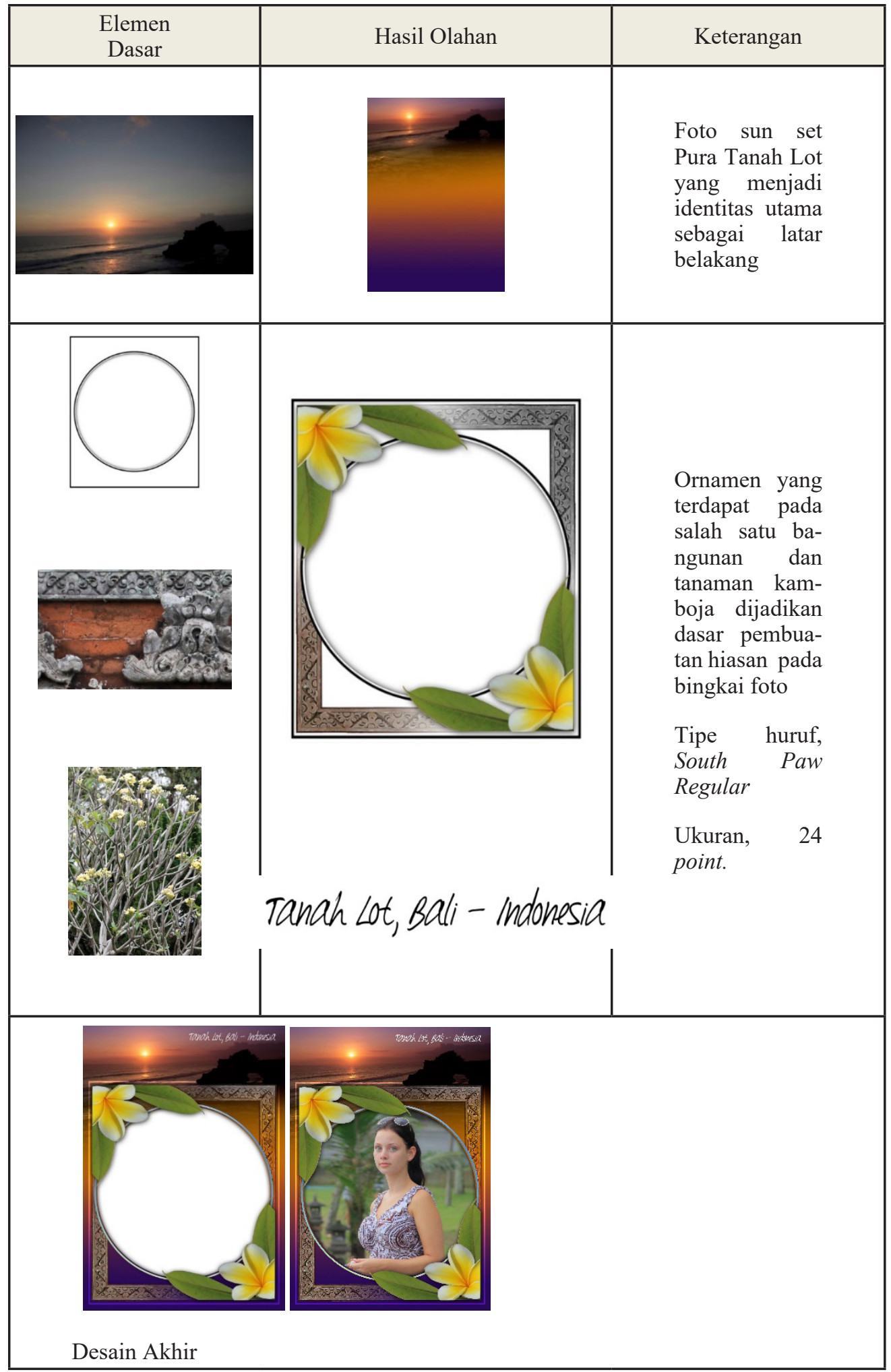


Tabel 3. Materi Desain : Obyek Wisata Taman Ayun

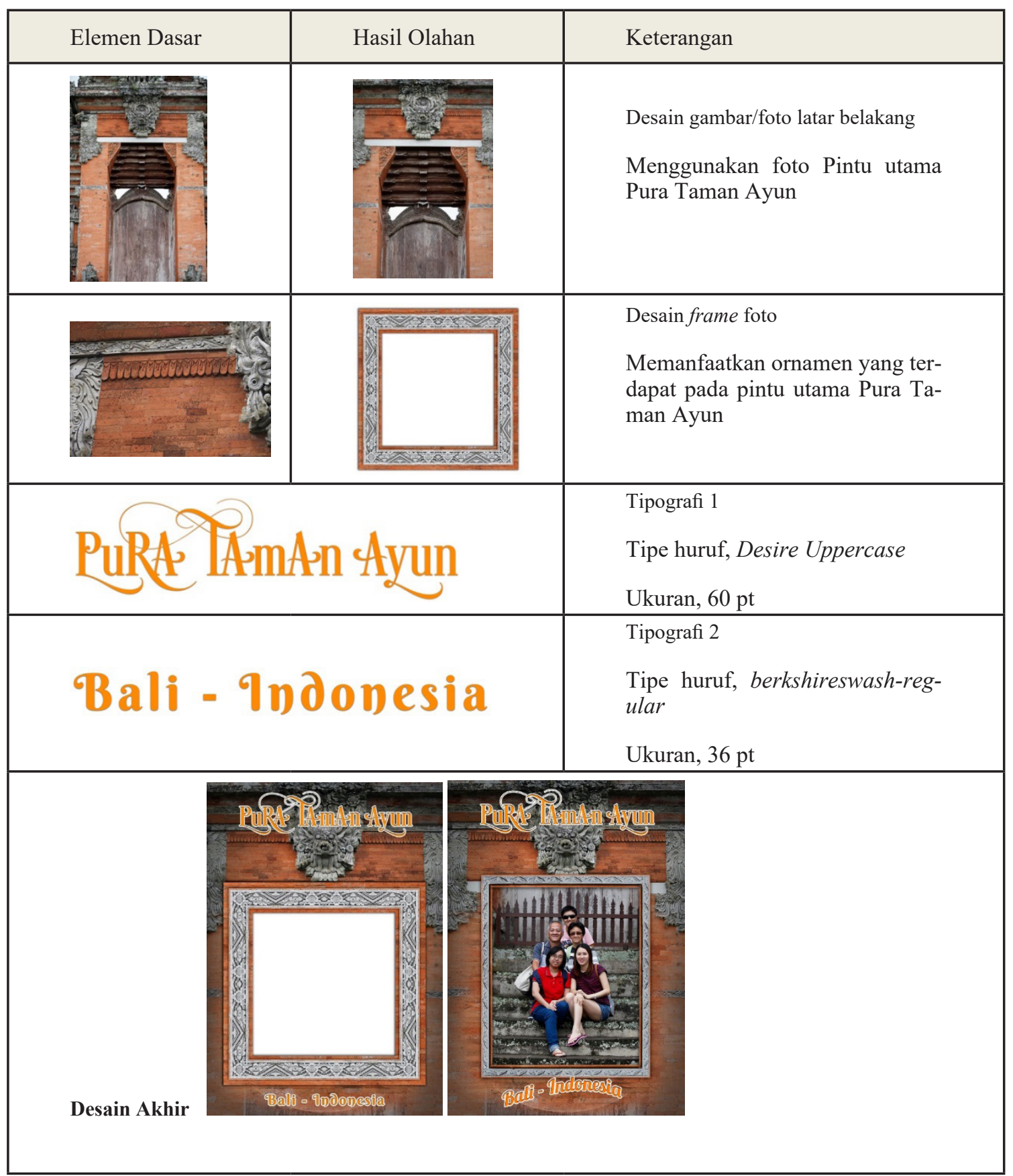

desain, masing-masing limabelas buah untuk Tanah Lot dan limabelas untuk Taman Ayun. Sedangkan pada tahap pernerapannya dilakukan di lokasi obyek wisata Tanah Lot dan Taman Ayun dengan desain siap pakai dan wisatawan dapat memilih desain tersebut sesuai dengan selera, tentunya dengan menyertakan foto wisatawan tersebut. Dengan demikian di manapun wisatawan dapat difoto dan tidak harus di depan obyek wisata tetapi bisa dilakukan di tempat parkir maupun di tempat penjualan oleh-oleh.

\section{SIMPULAN}

Jenis-jenis baju kaos yang dijual pada obyek wisata Pura Tanah Lot secara umum sama dengan apa yang dijual pada obyek wisata umumnya yang ada di Bali. Dari bahan yang digunakan sebagian besar menggunakan katun lacos, katun $20 \mathrm{~s}$ dan katun $32 \mathrm{~s}$ dengan varian harga Rp. 30.000 sampai dengan harga Rp. 1.000.000. Baju kaos dengan harga Rp. 30.000 dengan tingkat penjualan bagus. Baju kaos dengan 
harga Rp. 100.000 dengan tingkat penjualan bagus dan harga baju kaos Rp. 500-1.000.000 dengan tingkat penjualan sedang. Sedangkan tingkat kualitasnya dari yang sedang, bagus dan sangat bagus baik yang berwarna maupun hitam dan putih. Teknik pembuatannya menggunakan teknik sablon konvensional. Sedangkan desainnya sebagian besar bertemakan tentang seni dan budaya Bali dan sangat sedikit yang mencerminkan obyek wisata Pura Tanah Lot. Dari data yang diperoleh maka dapat disimpulkan bahwa sablon digital yang dilakukan dalam penelitian ini sangat memungkinkan menjadi solusi agar sovenir atau oleh-oleh yang dijual pada obyek tersebut mencerminkan obyek wisata Pura Tanah Lot yang memiliki identitas yag khas sangatlah tepat. tersebut.

Sedangkan Jenis-jenis baju kaos yang dijual pada obyek wisata Pura Taman Ayun secara umum sama dengan apa yang dijual pada obyek wisata umumnya yang ada di Bali. Dari bahan yang digunakan sebagian besar menggunakan katun lacos dan katun $20 \mathrm{~s}$ dengan varian harga Rp. 30.000 sampai dengan harga Rp. 100.000.. Baju kaos dengan harga Rp. 30.000 dengan tingkat penjualan sedang. Baju kaos dengan harga Rp. 100.000 dengan tingkat penjualan sedang. Sedangkan tingkat kualitasnya dari yang sedang dan bagus. baik yang berwarna maupun hitam dan putih. Teknik pembuatannya menggunakan teknik sablon konvensional. Sedangkan desainnya sebagian besar bertemakan tentang seni dan budaya Bali dan sama sekali belum mencerminkan obyek wisata Pura Taman Ayun.

Dari uji coba penerapan produk desain yang dilakukan dapat disimpulkan bahwa baik masyarakat yang mencari nafkah maupun para wisatawan memberikan apresiasi dan respon yang sangat positif. Pembuatan produk desain baju kaos dengan menerapkan fotografi dan sablon digital yang dilakukan dalam penelitian ini sangat memungkinkan untuk dikembangkan dan ditindaklanjuti sehingga menjadi solusi agar sovenir atau oleh-oleh yang dijual pada obyek tersebut mencerminkan obyek wisata Pura Tanah Lot dan Taman Ayun yang memiliki identitas yag khas dan memberikan alternatif baru serta menambah pendapat masyarakat.

\section{DAFTAR PUSTAKA}

Artini Kusmiati R., 1999. Terori Dasar Disain Komunikasi Visual, Djambatan, Jakarta.

Griand Giwanda. 2002. Panduan Praktis Menciptakan Foto Menarik, Puspa Swara, Jakarta., Surakarta.

Guntur, 2016, Metode Penelitian Artistik, ISI Press
Gustami SP. 2004."Proses Penelitian Seni Kriya Untaian Metodologis”.Makalah. PPS. ISI: Bali.

Ida Bagus Trinawindu, 2010, Kumpulan Abstrak Hasil Penelitian 2006-2018, LP2M Institut Seni Indonesia Denpasar,Denpasar.

Irwan, Sudayat: 2015, Sukses Membangun Industri Kreatif, Smart Pustaka, Yogyakarta.

Mikke Susanto:2002, Diksi Rupa, Kanisius, Yogyakarta

Mulyanta, Edi S: 2006, Teknik Modern Fotografi Digital, Andi Offset, Yogyakarta.

Nugroho R Amin: 2006, Kamus Fotografi, Andi, Yogyakarta

Pitana, I Gede: 2009, Pengantar Ilmu Pariwisata, Andi, Yogyakarta

Saryana, I Made: 2004, Handout Foto Ilustrasi, Tidak diterbitkan, Denpasar

Sudikan, Setya Yuwana. 2001. Metode Penelitian Kebudayaan. Surabaya: Citra Wacana.

Sukma Ariada, Nyoman, 2016, Dinamika Ekowisata Tri Ning Tri Di Bali, Pustaka Larasan, Denpasar Bali.

Wirakesuma, I Nengah, 2014, Segara Widya, Jurnal Hasil Penelitian Institut Seni Indonesia Denpasar, LP2M ISI,Denpasar.

--------Berlibur Di Kabupaten Badung Bali, 2014, Majalah Dinas Pariwisata Kabupaten Badung, Edisi II.

Jumpa, Jurnal Master Pariwisata, Volume 2 2016, Program Magister Kajian Pariwisata, Pascasarjana Universitas Udayana. 